\section{Spain has forgotten her scientists}

The politicians of newly democratic Spain are delaying urgent decisions on the future of science, writes Pedro Puigdomenech

\author{
Sorry, for copyright \\ reasons some images \\ on this page may not \\ be available online
}

ticipation of scientists. So it can be understood why the first reform of CSIC was to abolish its whole internal organisation.

Universities are overcrowded, after a boom in the number of students over the last ten years. This has imposed a large teaching load on the professors, and is one of the reasons why Spanish Universities are very far from doing the amount of research necessary to offer proper training facilities.

Many problems are common to both the CSIC and universities, and the lack of an adequate financing is one of them. The CSIC budget increased in the last years at a rate just comparable to inflation, but as salaries rose more quickly, staff expenditures corresponded to $85 \%$ of its budget in 1975 . Almost nothing is left for running costs. The problem is worse in universities where only the number of students and professors are normally taken into account in the distribution of credits. There is in theory a fund for research in universities (FIU) but it is distributed regardless of the research being done in the departments. The best one can expect is that the FIU will be spent on the students practical courses. Normally research in universities serves only to create PhDs; research work just stops after it.

Universities and the CSIC have a similar system of staff selection. This is a peculiar system of nationwide contest E called "oposiciones". It consists of a series of examinations, written, oral and practical. In the university they emphasise breadth of knowledge, so militating against specialised people. Research experience hardly favours a candidate at all. In any case the result is normally known in advance or can be forecast by looking at the composition of the jury.

Appointments to the CSIC involve somewhat different criteria but there the question is that staff positions are very rare. Scientific staff in CSIC has increased less than $10 \%$ in the last six years. So the average age of research staff -47 in 1971-has been increasing since then.

The winners of "oposiciones" are considered to be civil servants. There is no control at all on their activity but no possibility of a research career in front of them. In contrast a high proportion of the research $(100 \%$ in certain laboratories and departments) is done by staff 'under contract'. These contracts are for one year which means that most of the staff starts each year without a contract and will begin to be paid perhaps four months later. This situation can hardly be said to encourage research.

With very few exceptions, both CSIC institutes and University departments are far too small to be viable. The 
average number of posts in the CSIC institutes is 7 with very often more than 7 different lines of research being followed. More than 50 institutes have three positions or less. University departments have normally only one full professor and therefore no stable research groups of viable size. At the same time administrative work is multiplied increasing the bureaucratisation of the staff.

Finally most of research institutes are in Madrid, where $70 \%$ of the CSIC. staff are concentrated. This is especially serious for Spain where most of the industry is in two areas, Catalonia and the Basque Country. While only $5 \%$ of the CSIC research staff is in Catalonia, not a single research centre exists in the Basque Country; even the university has only recently been founded. It is not surprising then that research in Spain has no link with industry.

To coordinate the science policy in Spain an 'Advisory Commission for Scientific and Technical Research to the Prime Minister' was created in 1958. Its main function in recent years has been to distribute a fund (Fondo Nacional para el Desarrollo de la Investigacion Científica y Tecnica) that has been the only source of credit for research groups. This fund has the big advantage that credits are distributed to specific research projects that can last from one to four years. But, because of the poverty of the institutes and departments, everything--from salaries to running expenditures - is paid from these grants. This, plus the political desire to satisfy everyone, means that the fund is split into a large number of grants of insufficient size for the work to be undertaken.

For instance the latest available data (1975) show that $60 \%$ of the fund was divided among nearly 400 projects, totally unrelated one to another, to which less than 5 million pesetas $(\$ 60,000)$ were attributed for 4 years. Only 80 projects got more than this figure and they were limited to a small number of laboratories mostly in Madrid. The amount of credit is unrelated to the research topic and there is a widespread feeling that the credits received are independent of the quality of the proposed project.

However, it is especially difficult to organise an objective system of grant distribution in such a small scientific community as there is frequently only one specialist in any particular subject. This causes difficulties quite apart from the tendency to favour friends which some people claim to be the typical Spanish way of taking decisions. 'This is the reason why it has been proposed that foreign referees should be asked to take part, at least in grant committees.

Another important source of funds now declining was a programme of fellowships designed to train research workers (Plan de Formacion de Personal Investigador) that included financial help to laboratories. This has resulted in a large number of trained people, many with experience in laboratories abroad, who have not been able to find positions in the CSIC or industry. Therefore Spain has now hundreds of well trained research people either underemployed in Spain or working abroad (it has been calculated that $75 \%$ of Spanish physicists working in research are abroad).

The change to a more democratic system of government has led to great hope in the Spanish scientific community. It should mean the end of an arbitrary, antiscientific system. In the last two years new ideas and proposals have appeared and, for the first time, they are openly discussed. Commissions of scientific planning have been created in Parliament and a restricted 'Cabinet for Research and Development' has met for the first time in many years

Some reforms have already begun. In January 1977 the whole bureaucratic system of CSIC was abolishedalthough the CSIC still exists in name -and a new Statute issued in January 1978. It includes a Scientific Council with members elected by scientists $\left(60^{\prime \prime}\right)$ and a system for selection of directors of institutes in which the staff of institutes takes part. Long-term projects have been announced-such as a General Law for Scientific and Technological Research and a Law for Universities.

Nevertheless, the main decisions have not been taken and the state of research is very uncertain in the near future. A new team has been appointed for direction of CSIC. but it is the third in two years. The Advisory Commission, that may include some scientists from the first time, is preparing a National Plan for Research. Planning is essential for a country with limited financial resources but it is dangerous if it does not take into account the state of laboratories and the experience existing in them. However, the fund this Commission administrates may disappear; and it was the main source of credits for research. Autonomous governments have been appointed in several parts of Spain. beginning with Catalonia and the Basque Country. A congress of Catalan scientists asked recently for research to be put under the control of autonomous authorities, but such decisions are being taken very slowly.

There are several explanations for the delay that may cast a shadow on the scientists' hopes. All the reforms are being proposed in the midst of a deep economic crisis, and when there are other urgent political problems.

\section{Sorry, for copyright reasons some images on this page may not be available online}

Above: the science faculty of the 750-year-old
University of Salamanca. Opposite: overcrowding at the same University.

People in office do not seem to consider science as an urgent matter, and therefore very few things have changed. Opposition parties share the responsibility for this because they include only vague proposals for research in their political programmes. Among the peculiarities of the Spanish approach to democracy is the fact that people who were in some of the key posts in the preceding regime remain there. Therefore many people doubt their ability to introduce the necessary reforms.

Hundreds of Spanish scientists are now waiting for the decisions to be taken in the next few months. Some of them are abroad wating to come back if there is a minimum of change to enable serious work to be done. Some of them live in a continuous state of frustration under the precarious conditions in Spain. They are prepared to take part in the construction of the new economic and political system, if they are given a chance. In 1971 an OECD report on Spanish science concluded: "No nation if it is not to jeopardise its national character, can afford to be dependent for long on creative scientific activity carried out elsewhere". In 1978 it is to be seen if the newly democratic Spain will accept the challenge. 